\title{
PRESSUPOSTOS ACERCA DOS COMPONENTES FÍSICOS GEOGRÁFICOS NOS ANOS INICIAIS E O PAPEL DO PROFESSOR NO PROCESSO DE ENSINO E APRENDIZAGEM DOS CONTEÚDOS
}

\author{
Assumptions About Geographical Physical Components in Initial Years and the Teacher's Role \\ in the Teaching and Learning Process of the Contents \\ Izabelle de Cássia Chaves Galvão* \\ Adriana Olívia Alves** \\ Malu Ítala Araújo Souza*** \\ * Mestranda do PPG em Geografia - UFG - iza.chaves.93@gmail.com. \\ ** Professora do PPG em Geografia - UFG - dricasposito@yahoo.com.br. \\ *** Mestre pelo PPG em Geografia - UFG- maluitala 3@hotmail.com.
}

Recebido em 10/08/2018. Aceito para publicação em 20/08/2018.

Versão online publicada em 03/09/2018 (http://seer.ufrgs.br/paraonde)

\begin{abstract}
Resumo:
Este trabalho está consubstanciado na reflexão sobre a leitura de mundo, durante a construção do conhecimento dos escolares nos Anos Inicias. Possibilitar aos escolares que reconheçam o ambiente onde se relacionam, convivem e crescem, são algumas prerrogativas para que os elementos físicos possam compor a formação cidadã, potencializar e favorecer o raciocínio geográfico. Os objetivos desse trabalho estão pautados em, analisar a leitura de mundo, de forma que os conteúdos dos elementos físicos de Geografia tornem-se relevantes para os escolares que os aprendem. Acreditamos na potencialidade de ensinar esses conteúdos, tendo como ponto de partida a leitura de mundo, pois ela antecede a leitura da palavra. Cabe também neste texto, discutir questões relacionadas ao ensino de Geografia e formação de professores, a fim de compreender como os conteúdos são mobilizados tendo como referência a realidade.
\end{abstract}

Palavras-chave: Leitura de mundo; Anos Iniciais; Elementos Físicos.

\begin{abstract}
:
This work is consubstantiated in the reflection on the world reading, during the construction of the knowledge of the students in the Beginning Years. To enable schoolchildren to recognize the environment in which they interact, coexist and grow, are some prerogatives for physical elements to be able to compose citizenship formation, to enhance and favor geographic reasoning. The objectives of this work are based on analyzing the reading of the world, so that the contents of the physical elements of Geography become relevant for the students who learn them. We believe in the potentiality of teaching these contents, starting with the reading of the world, since it precedes the reading of the word. It is also in this text, to discuss issues related to the teaching of Geography and teacher training, in order to understand how the contents are mobilized with reference to reality.
\end{abstract}

Keywords: World reading; Initial Years; Physical Elements.

\section{Introdução}

Este trabalho está consubstanciado na reflexão sobre a leitura de mundo durante as séries finais dos 
Anos Iniciais. Neste contexto, refletimos sobre o processo de construção do raciocínio geográfico que pode se iniciar nessa fase escolar.

A escolha dessa seriação de ensino ocorre em virtude de ser nela da fase do letramento e o início do estudo dos conteúdos específicos de cada disciplina como os conteúdos dos elementos físicos da Geografia, que é o objetivo deste artigo. É nesta fase também, que as crianças passam a internalizar conceitos científicos e assim confronta-los com os conceitos cotidianos, adquiridos em suas experiências sociais e coletivas.

A escolha dos conteúdos relacionados aos componentes físicos geográficos ocorre, pois o estudo destes é relevante, recorrente e muito discutido no cotidiano dos escolares, principalmente em notícias vinculadas aos meios de comunicação, como, alterações temporais e climáticas que modificam os seres vivos e o planeta; fenômenos físicos do relevo que afetam e vulnerabiliza áreas da cidade; recursos naturais e sua disponibilidade nos lugares; sustentabilidade; e crescimento econômico (CARNEIRO, et al, 2007).

Possibilitar aos escolares que reconheçam a lugar onde vivem e relacionam, são algumas prerrogativas para que os componentes físicos geográficos possam ser significativos e problematizados na formação cidadã e, assim potencializar e favorecer o raciocínio geográfico.

Portanto, os objetivos desse trabalho estão pautados em, analisar a leitura de mundo, de forma que os conteúdos dos elementos físicos de Geografia tornem-se relevantes para os escolares que os aprendem e refletir acerca do papel docente do professor de Geografia nessa fase.

o lugar, como categoria para análise geográfica torna-se importante, pois possibilita aos alunos aproximar os conteúdos escolares a sua vivência, pois é nele que são estabelecidas as relações de pertencimento.

Nesse sentido, temos como propósito refletir acerca da temática do ensino de Geografia nos Anos Iniciais, de forma que saibamos reforçar a importância da ciência para o exercício da criticidade nos escolares do ensino básico, tendo como referência a formação cidadã.

Acreditamos que por meio da formação cidadã, os escolares podem compreender os elementos e fenômenos que ocorrem e compõe o seu lugar de vivência. Ao compreendê-los esses sujeitos podem atuar e refletir sobre sua realidade desde os primeiros anos de escolarização.

\section{Pressupostos a cerca do Ensino de Geografia nos Anos Iniciais}

A concepção do ensino de Geografia permite o entendimento das relações sociais e precisam ser observadas e somadas para o processo de ensino e aprendizagem do aluno. Esse processo está ligado a questões sociais, pois, o conhecimento que já foi adquirido em sua vivência será levado em consideração, para que os conteúdos sejam interessantes para os escolares e assim despertem neles a capacidade de assimilação à sua experiência vivida.

O ensino de Geografia, também proporciona a formação cidadã dos escolares, uma vez que a escola é um dos primeiros espaços de aprendizagem que corrobora para a construção de conhecimento científico e o pensamento crítico, de forma que, possibilite maior adaptação às diversas situações cotidianas, como aponta Cavalcanti (1998):

Trata-se de possibilitar os alunos a prática de pensar os fatos e acontecimentos enquanto constituídos de múltiplos determinantes: de pensar os fatos e acontecimentos mediante várias explicações, dependendo da conjugação desses determinantes, entre os quais se encontra o espacial. A participação de crianças e jovens na vida adulta, seja no trabalho, no bairro em que moram, no lazer, nos espaços de prática política explicita, certamente será de melhor qualidade se estes conseguirem pensar sobre seu espaço de forma mais abrangente e crítica. (p 24). 
Logo, o ensino de Geografia está para além de apenas a reprodução dos conteúdos e da memorização de determinadas regiões do globo. Compete então, ao professor estabelecer isso junto aos escolares em processo formativo, para que estes compreendam que a Geografia tem relevância e significado pra sua vida e atuação cotidiana.

Sabendo da importância do ensino de Geografia, precisamos refletir também acerca de sua importância para o escolar, uma vez que, ela é responsável em contribuir na percepção espacial do meio no qual ele está inserido e também possibilita a reflexão de suas práticas cotidianas.

Os alunos possuem alguns conhecimentos geográficos proveniente de suas relações diárias (CAVALCANTI, 2005), assim a Geografia vem auxiliar nesse processo de reconhecimento espacial do aluno, logo o professor precisa mediar os conteúdos escolares para contribuir de forma significativa na formação e construção de conceitos dos sujeitos que aprendem.

Neste contexto que estabelece a importância da Geografia como disciplina escolar, se dá nos Anos Iniciais, no qual possibilita a compreensão do que se estuda na escola, com sua vida cotidiana, deixando de ser um estudo distante e subjetivo (CALLAI, 2013). É também o momento em que o escolar aprende a ler e compreender o mundo, a vida e consequentemente, aprende a lidar e analisar o lugar em que vive, logo, ele aprende a viver o mundo e inicia o exercício da cidadania, em um contexto dos conceitos científicos.

A leitura de mundo, por vezes, antecede a leitura da palavra (CALLAI, 2013). Sendo assim, posteriormente, a leitura da palavra, pode dar continuidade e significado para a leitura de mundo.

Os Anos Iniciais são marcados pela fase na qual a criança tem seus primeiros confrontos entre os conceitos cotidianos e os conceitos científicos. Os professores precisam ensinar para seus alunos as devidas transformações ocorridas no mundo, sendo este integrado, de forma que se compreenda o presente e reflita sobre o futuro, o desafio para esses profissionais está em "[...] como aprender a ensinar a ler o mundo, a realidade em que vivemos, para que o aluno o faça também". (Callai 2013, p 136).

Conforme aponta Callai $(2005,2013)$ é importante nesta fase de ensino que o aluno aprenda a ler o mundo em vive. Já que as escolas de Anos Iniciais se dedicam ao ensino do letramento, cabe aos professores de Geografia promover também a alfabetização geográfica, procurando nesta fase de ensino, instigar os alunos a compreender o espaço em que vivem a partir da leitura, para que aprendam os conteúdos geográficos desde seus primeiros contatos com a escola. Callai (2005) nos mostra como promover esse letramento geográfico:

[...] é a partir de tais problemas que devem ser feitas a leitura, a representação, e que deve ser instigada a curiosidade para avançar na investigação e compreender o que ocorre. Mas não é preciso restringir a discussão à questão social, pode-se discutir questões que são específicas do conteúdo da disciplina Geografia, por exemplo, em vez de "ditar para o aluno", ou mesmo ler em um livro, ou responder a perguntas a partir de um texto, realizar a leitura do espaço. (p. 234).

Aprender a ler o mundo pode contribuir também para aprendizagem da leitura das palavras, Callai (2013) defende que, "o processo de alfabetização aconteceria de modo mais significativo se fosse realizado pela leitura do espaço e do mundo." (p137).

Compreender e ler o mundo corrobora para o exercício da análise geográfica, que só é possível quando desenvolvemos o olhar espacial, de forma que seja possível interpretar o que ocorre na sociedade (CALLAI, 2009).

Aliado à leitura de mundo, a categoria do lugar, pode contribuir no processo de ensino e aprendizagem dos alunos, pois é no lugar que os sujeitos escolares desenvolvem suas relações de 
pertencimento e identidade. Pois, "[..] ao trabalhar o estudo do Lugar com os estudantes cria-se a possibilidade de discutir a vida cotidiana e as exigências da sociedade em geral." (Callai, 2009, p 180).

Para que essas reflexões ocorram, é importante destacar a relevância de se ter um professor que visa e problematize os conhecimentos para além da realidade, mas também das categorias de análise da ciência que estuda e quais são seu aportes pedagógicos para ensiná-la.

\section{0 papel do professor na alfabetização geográfica}

O professor precisa conhecer seus escolares, para que compreenda a função do seu trabalho docente, pois o sujeito que aprende, também é possuidor de conhecimentos. Ao entender a realidade de seus estudantes e o quanto são diversos, o professor pode elaborar caminhos que tornem os conteúdos dos elementos físicos significativos e interessantes.

Diante disso, existem duas dimensões que estão interligadas a formação do professor de Geografia, uma denominada "função social" relacionada aos aspectos da formação pedagógica do professor e "função técnica" na qual o profissional desenvolve seu olhar espacial, portanto, aliar as duas funções pode contribuir na organização dos conhecimentos (CALLAI, 2009),

[...] a perspectiva técnica é aquela que se estende como instrumental para ensinar técnicas, ensinar a fazer coisas. E a perspectiva pedagógica é a que investe no ser humano, na capacidade de relação com o outro, de estabelecer a sincronia necessária para saber fazer, e de operacionalizar aquilo que sabe, de usar o instrumental necessário para compreender o Lugar. (p. 185).

Nesse sentido, o professor precisa considerar ambas as dimensões, para que seja possível mediar o processo de ensino e aprendizagem, a fim de que os sujeitos possam resolver tecnicamente questões e estabelecer um diálogo com a sociedade para que seja possível construir o conhecimento.

Sabendo disso, precisamos considerar que o professor de Geografia, durante seu processo formativo, passou por diversas etapas para se constituir como tal. Uma vez que, o professor antes de tudo é um sujeito social, que carrega consigo múltiplas experiências, com isso, tem uma noção prévia de como se constitui a carreira docente. (RICHTER, 2013).

Pimenta (2002) destaca que o professor, traz consigo experiências advindas de sua vida, desde a escola básica, onde ocorreram os primeiros contatos com os conhecimentos elementares (RICHTER, 2013). Na academia, esses conhecimentos, serão desenvolvidos afins de que, se tornem pensamento complexo, que por sua vez, serão ampliados durante a prática profissional, com ações e reflexões do exercício docente. Sendo que, o que foi aprendido na universidade, será adequado à realidade de sala de aula.

Aliado a esses aspectos da formação e do papel docente, acreditamos que o lugar, como categoria de análise geográfica pode contribuir na realização da análise espacial e desenvolvimento de um olhar geográfico, pois,

O lugar como ponto de referência ao ensino-aprendizagem da geografia não quer dizer que deva ser sempre o ponto de partida para o estudo. Pelo contrário o Lugar é a referência que nos possibilita interligar o cotidiano, a vida concreta, com as demandas do mundo global e trabalhando na interface do humano e do natural, compreender o mundo e a sociedade em que vivemos. (p 187).

Diante do exposto, ressaltamos que ao compreender o lugar, o escolar pode atribuir significado ao 
conteúdo aprendido na escola à vida cotidiana. Acreditamos desta forma, que os conteúdos dos componentes físicos geográficos, podem estar relacionados ao cotidiano do escolar, ao passo em que aluno compreende o lugar em que pertence, realiza leituras de mundo e assim, desenvolve sua análise geográfica. Compreender os componentes físicos geográficos nos auxilia a entender situações presentes em nosso cotidiano.

Neste sentido compreendemos a necessidade da disciplina de Geografia nos Anos Iniciais, para o início da construção do pensamento espacial, tendo em vista os diferentes componentes físicos geográficos que compõe o espaço. No próximo tópico iremos correlacionar a importância dessas temáticas, assim como o papel do professor no processo de ensino e aprendizagem destes conteúdos/temas/conceitos nos Anos Iniciais.

\section{Ensino dos conteúdos dos componentes físicos geográficos}

No ambiente escolar estudamos estes temas nas disciplinas de Geografia, Ciências e Biologia, mas é na Geografia que trabalhamos estes conteúdos de forma a compreendê-los no espaço em que estamos inseridos, por isso consideramos como componentes físicos geográficos. Compete a disciplina de Geografia construir nos escolares um raciocínio espacial crítico e consciente do seu papel na sociedade.

Ao tratar dos conteúdos dos elementos físicos da Geografia, precisamos ir além das características e conceitos prontos, temos que demonstrar os aspectos sociais diante da natureza de maneira integralizada, para que o aluno aprenda a refletir sobre sua realidade. Nesse sentido Suertegaray (2000) diz que, para se ensinar Geografia Física:

[...] faz-se necessário repensar-se o ensino da Geografia (Física?), de maneira que ela efetivamente contribua para o reconhecimento mais substantivo do espaço vivido. Para além da fixação dos conceitos, o conhecimento da realidade que se habita favorece ao desenvolvimento da criticidade, criatividade e, quiçá, a busca da transformação, ou seja, a educação para a participação. (p. 105).

Desta forma, nós professores precisamos considerar o lugar de vivência dos alunos, para que o ensino seja de fato, um elemento de transformação na vida dos escolares.

É notório que ainda se trabalhe esses conteúdos de forma mnemônica, pautado na memorização de conceitos pré-estabelecidos. Para que o ensino dessas temáticas seja significativo aos escolares é válido que, estes sejam relacionados ao cotidiano de quem o aprende.

Nesse sentido, Morais (2013) sugere que o ensino tenha como referência a escala de análise, no qual permita a compreensão do vivido, das relações sociais cotidianas. Assim, a autora trabalha o conteúdo do relevo partindo da vertente, indo além de explicar esse conteúdo pautando somente nas macroformas.

Outra forma de se trabalhar essas temáticas de forma significativa é compreender também que todos os componentes físicos estão interligados de forma dinâmica e acíclica na paisagem. Também é de se considerar que não é possível trabalhar os conteúdos sem considerar a espacialidade, pois ela é a responsável em nos ajudar a compreender e estabelecer um raciocínio geográfico (ROQUE ASCENÇÃO E VALADÃO, 2013).

Os mesmos autores acreditam que, uma vez que os conhecimentos da Geografia são trabalhados tendo como referência a espacialidade (em interação com os conteúdos) é possível entender um fenômeno e como este se manifesta no espaço geográfico.

É comum que os professores ao serem questionados sobre, o que lecionam em sala de aula digam que se trata de um conteúdo isolado, tratando esse conhecimento como algo definitivo e obrigatório, sem 
levar em consideração que se trata de uma seleção de conteúdos de âmbito político e pedagógico (ROQUE ASCENÇÃO e VALADÃO, 2013), o que demonstra que, muitas vezes, para os professores, o conteúdo é o fim e não uma forma de compreender a totalidade.

Os mesmos autores citam o exemplo do ensino do conteúdo de clima na Geografia:

[...] as abordagens dos componentes espacial clima se atém ao estudo informativo sobre a distribuição climática, a diferenciação conceitual entre clima e tempo e a conceituação de elementos climáticos: pluviosidade; temperatura; umidade. Tratam esse componente espacial de forma estanque em relação aos demais, sem que se invista no desenvolvimento de um raciocínio geográfico e, consequentemente, na interpretação de uma dada espacialidade. (p $50)$.

Entende-se que o professor, precisa relacionar os conteúdos ensinados, independente de sua especificidade, tendo como referência principal o objetivo da Geografia, o de reflexão espacial, pois, somente assim, o escolar compreenderá os fenômenos que ocorrem a sua volta, e irá associá-los aos conteúdos aprendidos na escola e formar um raciocínio geográfico.

No que se refere ao estudo dos conteúdos dos elementos físicos, tendo como referência uma abordagem integrada, Morais (2013), ao tratar do relevo, reforça que:

Ao selecionarmos o relevo, as rochas e os solos como uma referência para o estudo das temáticas físico-naturais na geografia escolar, não buscamos entendê-los como elementos isolados, pois acreditamos que, para a compreensão dos processos que envolvem a sua origem e a dinâmica atual, é imprescindível a compreensão do papel desempenhado pelo clima, pelo material de origem, pela rede hidrográfica, pelos organismos vegetais e animais e pelo tempo no que se refere a cada um e às interações existentes entre eles. (p 21).

Para compreender esses fenômenos que ocorrem no espaço geográfico, precisamos então, entender que tudo está integrado. Nós inclusive, como seres biológicos também somos responsáveis pelas alterações naturais ou não que acontecem no lugar em que estamos inseridos (MORAIS, 2013). Por isso, precisamos ter consciência dessa integração para que os escolares também possam relacionar sua prática cotidiana ao lugar em que vive.

Podemos então, procurar correlacionar os alunos aos termos e conceitos cotidianos geográficos, para que busquem associações para suas experiências cotidianas dentro e fora de sala de aula. Para que o processo de ensino e aprendizagem ocorra, é necessário que se construa junto com os escolares, ao passo que o aluno é o centro deste processo e o professor, o agente mediador (MORAIS,2013).

A construção do conhecimento está pautada nas relações entre o objeto do conhecimento e o sujeito que o aprende, essas relações acontecem de forma natural, simples ou mecânica levando em conta como o conteúdo é ensinado e como o professor media o mesmo, de forma que seja possível desenvolver o pensamento complexo (CASTELLAR E SOUZA, 2016).

As mediações que o professor utiliza são carregadas de intencionalidades, tendo como ponto de partida, o conhecimento prévio do escolar e o conhecimento da ciência específica (Geografia), logo as mediações realizadas pelos professores é denominada de mediação didática. (D’ÁVILLA, 2008).

Nesse sentido, a realidade vivida pelo aluno e os conhecimento teóricos aprendidos na ação da mediação, contribuem na construção dos conceitos, tendo como referência mundo em que vive.

\section{Considerações Finais}


Ao refletirmos sobre o ensino, temos que ter o cuidado de considerar que não existe um único caminho ou forma de se ensinar. 0 processo de ensino e aprendizagem abarca diversas situações externas à sala de aula, no que se refere à vida dos sujeitos envolvidos nesse processo.

Nesse sentido, propusemos nesse trabalho, o ensino dos conteúdos dos elementos físicos da Geografia nos Anos Iniciais, tendo como ponto de partida a leitura de mundo, pois ela antecede a leitura da palavra dos escolares. Ao conhecer a palavra que justifique determinado fenômeno já observado e conhecido pelo escolar no seu cotidiano, ela adquire um significado no processo de alfabetização.

0 ensino dos conteúdos relacionados aos componentes físicos geográficos pode ser um instrumento, capaz de fazer o escolar entender às dinâmicas espaciais e sociais. Assim, ele pode compreender os conteúdos de Geografia de forma integrada e significativa.

Acreditamos na potencialidade desses componentes físicos para a compreensão e entendimento espacial durante a fase de alfabetização geográfica nos Anos Iniciais. Ressaltamos assim, que diante desses pressupostos, os escolares sempre serão o centro do processo de ensino e aprendizagem e os professores agentes mediadores.

\section{Referências}

ASCENSÃO, V. DE O. R.; VALADÃO, R. C. Abordagem do conteúdo "RELEVO" na educação básica. In: CAVALCANTI, L. DE S. Temas da geografia na escola básica. Campinas, SP: Papirus, 2013.

CALLAI, Helena C. Aprendendo a ler o mundo: a geografia nos anos iniciais do ensino fundamental. Cad. Cedes, Campinas, vol. 25, n. 66, p. 227-247, maio/ago. 2005. Disponível em: < http://www.scielo.br/pdf/ccedes/v25n66/a06v2566.pdf > (acesso em: 28 de dezembro de 2015, às 09:20).

CALLAI, H.C. A formação do profissional da geografia - o professor. Ijui. Editora Unijui.2013.

CALLAI, H.C. O lugar e o Ensino - apredizagem da Geografia. In: PEREIRA, M.G.(orgs). La espesura del lugar: reflexiones sobre el espacio en el mundo educativo. Santiago: Universidad Academia, 2009. p 198-217.

CARNEIRO, Celso D. R. BARBOSA, Ronaldo. PIRANHA, Joseli M. Bases teóricas do projeto Geo-escola: uso de computador para ensino de Geociências.Revista Brasileira de Geociências. 37, 2007. P 90-100.

CAVALCANTI, Lana de S. Geografia, escola e construção de conhecimentos. Campinas-SP: Papirus, 1998.

Cotidiano, mediação pedagógica e formação de conceitos: uma contribuição de Vygotsky ao ensino de Geografia. Cadernos do CEDES, São Paulo, n. 66, maio/ago. 2005.

A Geografia e a Realidade Escolar Contemporânea: Avanços, Caminhos, Alternativas. ANAIS DO I SEMINÁRIO NACIONAL: CURRÍCULO EM MOVIMENTO - Perspectivas Atuais Belo Horizonte, novembro de 2010. Disponível em <http://portal.mec.gov.br/docman/dezembro-2010-pdf/7167-3-3geografia-realidade-escolar-lana-souza/file> (acesso em: 23/12/2015 às 10:25).

D'ÁVILA, Cristina. Decifra-Me Ou Te Devorarei: O Que Pode O Professor Frente Ao Livro Didático?. 1.ed. SALVADOR: EDUFBA e EDUNEB, 2008. v. 1. 190p

FREIRE, Paulo. A importância do ato de ler. In: Freire, Paulo. A importância do ato de ler: em três artigos que se complementam. SP: Autores Associados: Cortez, 1989.

MORAIS, Eliana Marta Barbosa de. O ensino das temáticas físico-naturais na Escolar. 2011. Tese - USP/ Universidade de São Paulo- Programa de Pós-Graduação em Geografia. Disponível em<http://www.teses.usp.br/teses/disponiveis/8/8136/tde-13062012-122111/pt-br.php>. Acesso em: $13 / 01 / 2016$.

As temáticas físico-naturais como conteúdo de ensino de Geografia escolar. In.: Temas da Geografia 
na Escola Básica. Campinas, São Paulo. Papirus. 2013. p 13-44.

PIMENTA, Selma Garrido. (Org.) Saberes pedagógicos e atividade docente. 3. ed. São Paulo: Cortez, 2002.

RICHTER, Denis. Os desafios da Formação do Professor de Geografia: O Estágio Supervisionado e sua articulação com a escola. In: SILVA, E. I \& PIRES, L. M. (ORGs). Desafios da Didática da Geografia. Goiânia: Ed. PUC Goiás, 2013.

SANTOS, M. A Natureza do Espaço. Técnica e Tempo. Razão e Emoção. 2o Edição. São Paulo: Hucitec, 1997.

SUERTEGARAY, Dirce Maria Antunes. O que ensinar em Geografia (Física)? In: Geografia e educação: geração de ambiências. REGO, Nelson (et al.). Porto Alegre: Ed. Universidade/UFRS, 2000. 